Toxicological and Environmental Chemistry, Vol. 67, pp. 491-510 Reprints available directly from the publisher

Photocopying permitted by license only
(C) 1998 OPA (Overseas Publishers Association) N.V. Published by license under the Gordon and Breach Science Publishers imprint. Printed in India.

\title{
ORGANOTIN POLLUTION IN MALTA COASTAL ZONE
}

\author{
ALFRED J. VELLA ${ }^{a} * *$ BERNARDETTE MINTOFF ${ }^{a}$, \\ VICTOR AXIAK $^{b}$, DORITA AGIUS ${ }^{b}$ and ROBERTO CASSONE ${ }^{b}$ \\ ${ }^{a}$ Department of Chemistry, ${ }^{\mathrm{b}}$ Marine Ecotoxicology Laboratory, \\ Department of Biology, University of Malta, Masida, Malta
}

(Received 10 March 1997; Revised 2 September 1997)

\begin{abstract}
The speciation of organotins in seawater, surface microlayer and sediments in the marine environment of Malta is described. Concentrations of tributyltin (TBT) in bulk seawater inside the harbours were as high as $0.3 \mu \mathrm{g} \mathrm{Sn} \mathrm{L}^{-1}$ but were below detection limits $\left(5 \mathrm{ng} \mathrm{Sn} \mathrm{L}{ }^{-1}\right)$ in open sea, $1.6 \mathrm{~km}$ offshore. In sediments, TBT levels were highest for the yacht marinas and ranged between 0.03 and $1.5 \mu \mathrm{g} \mathrm{Sn}^{-1}$. Dibutyltin is more common in the surface microlayer than TBT. Diphenyl and monophenyltin were found infrequently in bulk seawater and in sediments. Tetrasubstituted organotins, namely, $\mathrm{Me}_{n} \mathrm{Bu}_{(4-n)} \mathrm{Sn}$, where $n=1,2$, and 3, were found frequently in TBT-contaminated sediments $\left(0.1-9 \mu \mathrm{gSn} \mathrm{g}^{-1}\right)$, in seawater and in the microlayer where concentrations as high as $140 \mu \mathrm{g} \mathrm{Sn} \mathrm{L}^{-1}$ ( $\left.\mathrm{Me}_{3} \mathrm{BuSn}\right)$ were measured. Direct environmental methylation of TBT and that of its debutylated analogues may play a significant role in the geochemical cycling of tin under certain environmental conditions.
\end{abstract}

Keywords: Organotin; tributyltin; pollution; methylbutyltin; marine; Malta

\section{INTRODUCTION}

Tributyltin (TBT) compounds, $\mathrm{Bu}_{3} \mathrm{SnX}(\mathrm{X}=$ carboxylate, chloride, hydroxide etc.), represent a major input of organotins in the environment and concern over the impact caused by these compounds has spawned a considerable literature. TBT is used mainly as an antifouling agent in paints for ships, boats and docks. Besides TBT and its dealkylated metabolites, namely, dibutyltin (DBT) and monobutyltin (MBT), there are other organotin forms which are frequently encountered in coastal marine environments. Phenyltin

* Corresponding author. 
species, $\mathrm{Ph}_{n} \mathrm{Sn}^{(4-n)+}, n=1,2$ and 3 , have been reported in seawater and sediments [1-3] and a major anthropogenic source for these forms is $\mathrm{Ph}_{3} \mathrm{Sn}^{+}$ which is also used in antifouling marine paints and as an agricultural pesticide [5]. The biogeochemistry of tin is also influenced by the formation of methyltin forms, $\mathrm{Me}_{n} \mathrm{Sn}^{(4-n)+}, n=1-4$, which are reported to be ubiquitous in seawater and in sediments, macroalgae, plants and fish [6]. These organotins are believed to originate mainly by biotic [7-9] or abiotic [10,11] methylation of inorganic tin, $\mathrm{Sn}^{4+}$. Biotic transformation of tin can also conduce to the formation of stannane, $\mathrm{SnH}_{4}$, and methylstannanes, $\mathrm{Me}_{n} \mathrm{SnH}_{(4-n)}$, depending on conditions [12]; methylstannanes with $n=2,3$ and also $\mathrm{BuSnH}_{3}$ have been detected in seawater [13]. Additional geochemical pathways must be available in order to account for the presence of methylbutyltins $\mathrm{Bu}_{3} \mathrm{MeSn}$ and $\mathrm{Bu}_{2} \mathrm{Me}_{2} \mathrm{Sn}$ which were first reported by Maguire [14].

In this paper, we present data on the presence of TBT, DBT and MBT compounds in seawater, surface microlayer and sediments collected from the coastal zone of the Maltese islands. We also give data on other organotin forms which were encountered in these environmental phases. This is the first detailed report on organotin pollution in a central Mediterranean site where no regulatory restrictions on the use of TBT are yet in place. We discuss the significance of our findings in relation to local inputs of organotins and compare the pollution status of the Malta coastal zone with that of other Mediterranean sites.

\section{MATERIALS AND METHODS}

Butylpropyltins $\left(\mathrm{Bu}_{n} \operatorname{Pr}_{(4-n)} \mathrm{Sn}\right)$, butylmethyltins $\left(\mathrm{Bu}_{n} \mathrm{Me}_{(4-n)} \mathrm{Sn}\right)$, methylpropyltins $\left(\mathrm{Me}_{n} \operatorname{Pr}_{(4-n)} \mathrm{Sn}\right)$ and phenylpropyltins $\left(\mathrm{Ph}_{n} \operatorname{Pr}_{(4-n)} \mathrm{Sn}\right)$ were prepared and purified according to the method of Maguire and Huneault [15]. The environmental samples were collected from thirteen stations along the eastern coastline of Malta and one station on Gozo (Figure 1) during the periods June/July 1993, September/October 1993 and January/February 1994. The distribution of these stations effectively covered a significant part of the eastern coastline of the Malta mainland and included the port and harbour areas; most of the Malta western coast is inaccessible cliff and is devoid of berths for sea craft. One station was sited $1.6 \mathrm{~km}$ offshore Grand Harbour. As indicated in Table I, the collection sites varied widely with respect to degree of circulation, boat densities as well as the presence of likely sources of organotin contamination deriving from shipyard or yacht marina activities. Bulk seawater (40 samples) and surface microlayer ( 70 samples) 


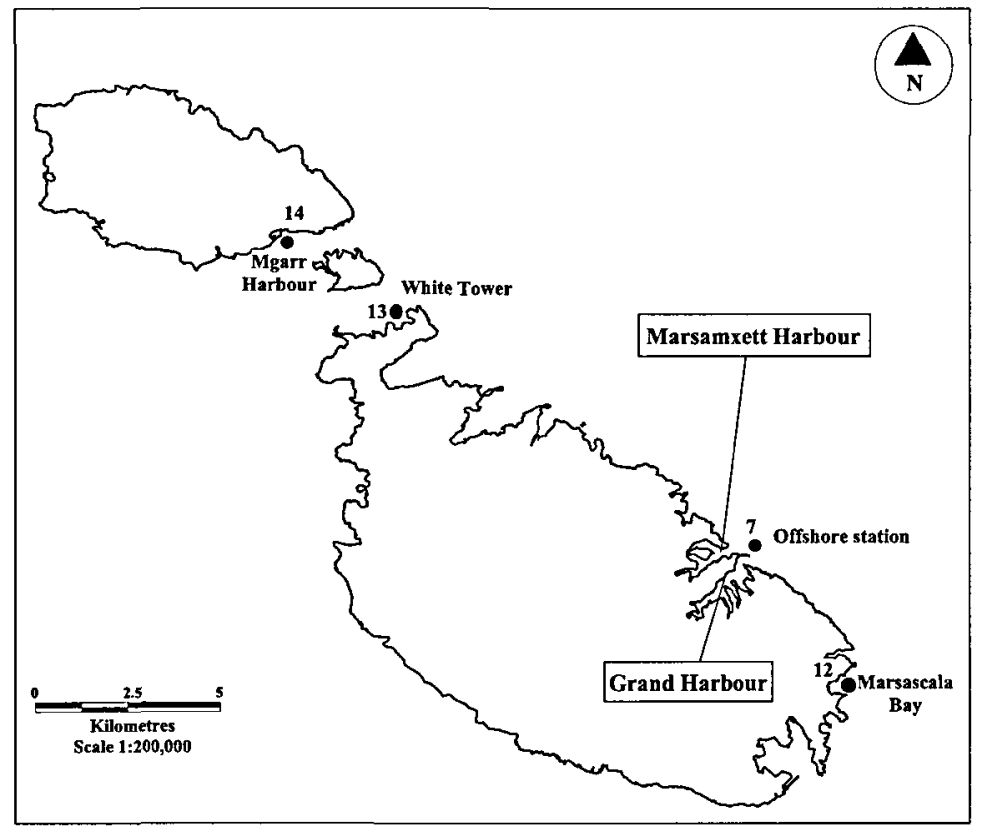

FIGURE 1(a) Map of Maltese islands (Central Mediterranean) showing location of sites sampled.

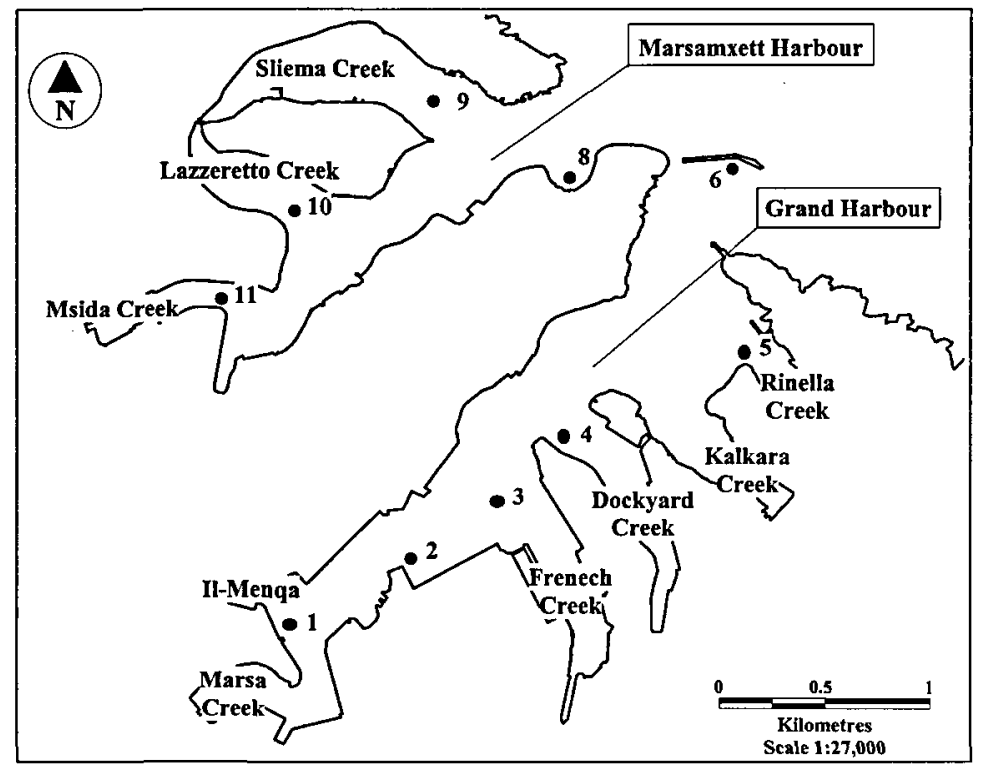

FIGURE 1(b) Detail of Malta harbour areas. 
TABLE I Description of sites of collection

\begin{tabular}{|c|c|}
\hline Site & Features \\
\hline 1. Marsa & within Grand Harbour, next to Power Station \\
\hline 2. Ras Hanzir & within Grand Harbour \\
\hline 3. French Creek & area of major shipyard \\
\hline 4. Dockyard Creek & area of major shipyard \\
\hline 5. Rinella Creek & $\begin{array}{l}\text { next to reception facility for oily ballast, near major } \\
\text { shipyards }\end{array}$ \\
\hline 6. St Elmo Point & at mouth of Grand harbour \\
\hline 7. Site offshore Grand & open sea $1.6 \mathrm{~km}$ outside Grand Harbour \\
\hline 8. Marsamxett Harbour & area at mouth of harbour \\
\hline 9. Sliema Creek & near major yacht marina and yacht repair yard \\
\hline 10. Lazzaretto Creek & major yacht marina \\
\hline 11. Msida Creek & major yacht marina \\
\hline 12. Marsascala & open and exposed coastline; moderate boat traffic \\
\hline 13. White Tower Bay & good exchange with open seas; low boat traffic \\
\hline 14. Mgarr Harbour, Gozo & major harbour serving inter-islands boat traffic \\
\hline
\end{tabular}

were collected from sites $1-11$ while sediments ( 28 samples) were collected from all sites except 4, 7 and 9.

Seawater samples (2 L), collected with a Van Dorn sampler, were placed, unfiltered, in amber coloured glass bottles and were acidified with acetic acid $(5 \mathrm{~mL})$. The samples were generally collected from a depth of $1 \mathrm{~m}$ but, on one occasion and for two sites only, they were obtained from three different water depths. Microlayer samples were recovered using a glass plate $(0.2 \mathrm{~m}$ square and $4 \mathrm{~mm}$ thickness) introduced perpendicularly to the water surface [16]; the thickness of the microlayer was $75 \pm 10 \mu \mathrm{m}$. About $100 \mathrm{~mL}$ of microlayer was collected and treated in a similar manner to seawater samples. Sediments were collected by an Ekman-Birge bottom sampler and the top 2-3 cm layer of sediment was separated and stored in a polycarbonate bottle at $-20^{\circ} \mathrm{C}$ pending analysis.

\section{Extraction Procedure}

Seawater and microlayer samples were extracted within $24 \mathrm{~h}$ of collection by a procedure based on that of Waldock et al. [17] and modified as follows. A volume of $2 \mathrm{~L}$ seawater was first spiked with $700 \mathrm{ng}$ tripentyltin chloride in methanol (as a recovery standard) and then extracted with $100 \mathrm{~mL}$ dichloromethane containing $0.0125 \%$ tropolone. For the surface microlayer, the volumes of sample and extractant were respectively 100 and $30 \mathrm{~mL}$. The extract was dried (sodium sulfate), reduced in volume by rotary evaporation at room temperature and transferred quantitatively to a glass vial where its volume was taken down to about $0.5 \mathrm{~mL}$ under a stream of nitrogen. The vial 
was stored at $-20^{\circ} \mathrm{C}$ pending derivatisation and gas chromatographic analysis.

Sediments were extracted by a method based on that of Ashby and Craig [18]. After wet sieving through a $67 \mu \mathrm{m}$ mesh, $4 \mathrm{~g}$ of wet sediment were spiked with $700 \mathrm{ng}$ tripentyltin chloride in methanol and then treated with $20 \mathrm{~mL}$ water and $5 \mathrm{~mL}$ hydrochloric acid and left to stand overnight.

The mixture was extracted with $25 \mathrm{~mL}$ dichloromethane/tropolone. After drying, the separated extract was further treated as for the aqueous samples.

\section{Derivatisation of Extracts and Analysis by Gas Chromatography}

The extract was dissolved in $2 \mathrm{~mL}$ hexane and derivatised by treatment with propylmagnesium bromide in ether $(1 \mathrm{~mL}, 2 \mathrm{M})$. After acid work-up, the organic matter was taken up in hexane and the solution applied to a silica gel 60 column $(5 \mathrm{~g})$ capped by sodium sulfate and eluted with hexane. The eluate was evaporated under nitrogen to about $2 \mathrm{~mL}$, transferred quantitatively to a vial containing $600 \mathrm{ng}$ tetrabutyltin as internal standard and the total volume carefully reduced to $100 \mu \mathrm{L}$. Gas chromatography was performed using a Perkin Elmer Model 8000 gas chromatograph equipped with a flame photometric detector and a $610 \mathrm{~nm}$ filter. A $25 \mathrm{~m}$ fused silica narrow bore capillary column with a nonpolar bonded phase (BP1, SGE Australia) was used. A second column having identical physical dimensions but carrying a more polar phase (BP10, SGE Australia) was employed for confirmatory purposes. Peak identities were confirmed by co-chromatography with authentic standards and, where possible, samples were also analysed by gas chromatography-mass spectrometry using an ion trap detector (ITD) (Finnigan Mat).

A mixture containing propylated butyltins in hexane prepared daily from concentrated standard solutions was used to test the performance of the gas chromatograph. Appropriate reagent/solvent blank analyses were performed routinely as controls to assure quality.

We established recovery efficiencies from water using solutions of organotin chlorides (or the tetraorganotin) in acidified distilled water containing between 5 and $8 \mu \mathrm{g} \mathrm{Sn} \mathrm{L}^{-1}(N=3)$. Recoveries from sediments were performed on spikes of $4-5 \mu \mathrm{g} \mathrm{Sn}^{-1}(N=3)$. The results are shown in Table II.

Except for the data on tetraalkyltins, these values are corrected on the basis of the recovery of $\mathrm{Pe}_{3} \mathrm{SnCl}$. The very low extraction efficiency for $\mathrm{Me}_{3} \mathrm{BuSn}$ probably results from the volatility of the compound and may partly explain why its presence in environmental samples has rarely been 
TABLE II Percentage extraction efficiencies; values for butyl, methyl and phenyltins are corrected with respect to recovery standard $\mathrm{Pe}_{3} \mathrm{Sn}^{+}$(for all compounds, $N=3$ )

\begin{tabular}{lcc}
\hline Organotin & \multicolumn{2}{c}{ Extraction efficiency } \\
\cline { 2 - 3 } & Distilled water & Sediment \\
\hline $\mathrm{Bu}_{3} \mathrm{Sn}^{+}$ & $97 \pm 2$ & $77 \pm 13$ \\
$\mathrm{Bu}_{2} \mathrm{Sn}^{2+}$ & $74 \pm 5$ & $58 \pm 6$ \\
$\mathrm{BuSn}^{3+}$ & $61 \pm 19$ & $30 \pm 5$ \\
$\mathrm{Me}_{3} \mathrm{Sn}^{+}$ & $2 \pm 1$ & $23 \pm 5$ \\
$\mathrm{Me}_{2} \mathrm{Sn}^{2+}$ & $39 \pm 7$ & $53 \pm 5$ \\
$\mathrm{MeSn}^{3+}$ & $54 \pm 24$ & $19 \pm 10$ \\
$\mathrm{Ph}_{3} \mathrm{Sn}^{+}$ & $53 \pm 4$ & $47 \pm 4$ \\
$\mathrm{Ph}_{2} \mathrm{Sn}^{2+}$ & $74 \pm 14$ & $32 \pm 8$ \\
$\mathrm{PhSn}^{3+}$ & $32 \pm 6$ & $20 \pm 7$ \\
$\mathrm{BuMe}_{3} \mathrm{Sn}$ & $9 \pm 3$ & $13 \pm 4$ \\
$\mathrm{Bu}_{2} \mathrm{Me}_{2} \mathrm{Sn}$ & $37 \pm 5$ & $25 \pm 2$ \\
$\mathrm{Bu}_{3} \mathrm{MeSn}$ & $69 \pm 7$ & $26 \pm 4$ \\
\hline
\end{tabular}

reported. Recoveries are also poor for propylated methyltins and it is clear that the analytical technique is not adequate for these volatile organotins.

Our instrumental detection limit for TBT, DBT and MBT was $100 \mathrm{pg}$ Sn injected for each organotin compound and corresponds to a signal/noise ratio of about 3. For TBT, this corresponds to $5 \mathrm{ng} \mathrm{Sn} \mathrm{L}^{-1}$ for aqueous solutions and $7 \mathrm{ng} \mathrm{Sn}^{-1}$ for sediments assuming mean rates of recovery as obtained from spiking experiments. Concentration values quoted in this work are adjusted to account for rates of extraction as determined in spiking experiments.

\section{Problem of Co-Elution of Analytes}

The nonpolar column used in this work for gas chromatography separates tetraalkyltins on the basis of their boiling point and affinity for the phase: these parameters increase with the molecular size of the analytes. Using standards, we established that $\mathrm{MeBu}_{3} \mathrm{Sn}$ coelutes with isomeric $\mathrm{BuPr}_{3} \mathrm{Sn}$, the product of propylation of monobutyltin. The ITD mass spectra of $\mathrm{MeBu}_{3} \mathrm{Sn}$ and $\mathrm{BuPr}_{3} \mathrm{Sn}$ (Figure 2(a)) possess highly characteristic isotopic clusters belonging to tin-containing fragment ions but lack the molecular ion cluster. Fragment ion clusters with $m / z$ values $131-139$ and $189-198$ corresponding, respectively, to debutylated fragments $[\mathrm{MeSn}]^{+}$and $[\mathrm{BuMeSn}]^{+}$occur exclusively in the mass spectrum of $\mathrm{MeBu}_{3} \mathrm{Sn}$ while fragments with $m / z$ values $161-167,205-211$ and $259-265$ corresponding, respectively, to $[\mathrm{PrSn}]^{+},\left[\mathrm{Pr}_{2} \mathrm{Sn}\right]^{+}$and $\left[\mathrm{BuPr}_{2} \mathrm{Sn}\right]^{+}$characterize $\mathrm{BuPr}_{3} \mathrm{Sn}$. Hence by 
analyzing the mass spectra in the total ion chromatographic peaks we could determine whether propylated monobutyltin was eluting singly or together with $\mathrm{MeBu}_{3} \mathrm{Sn}$. By performing multiple ion monitoring we could increase the sensitivity of the ITD and obtain better results on the more dilute samples.
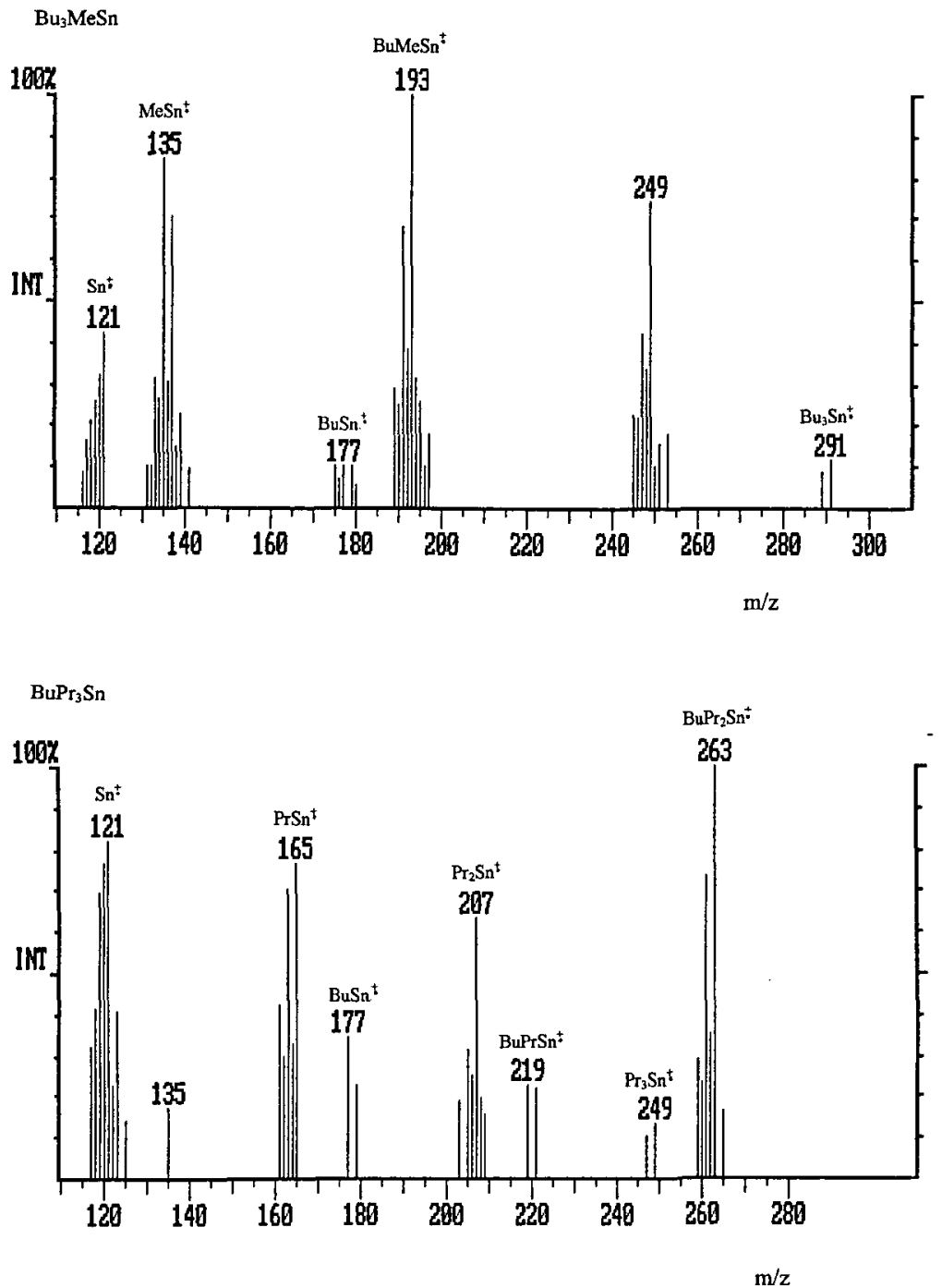

FIGURE 2(a) 

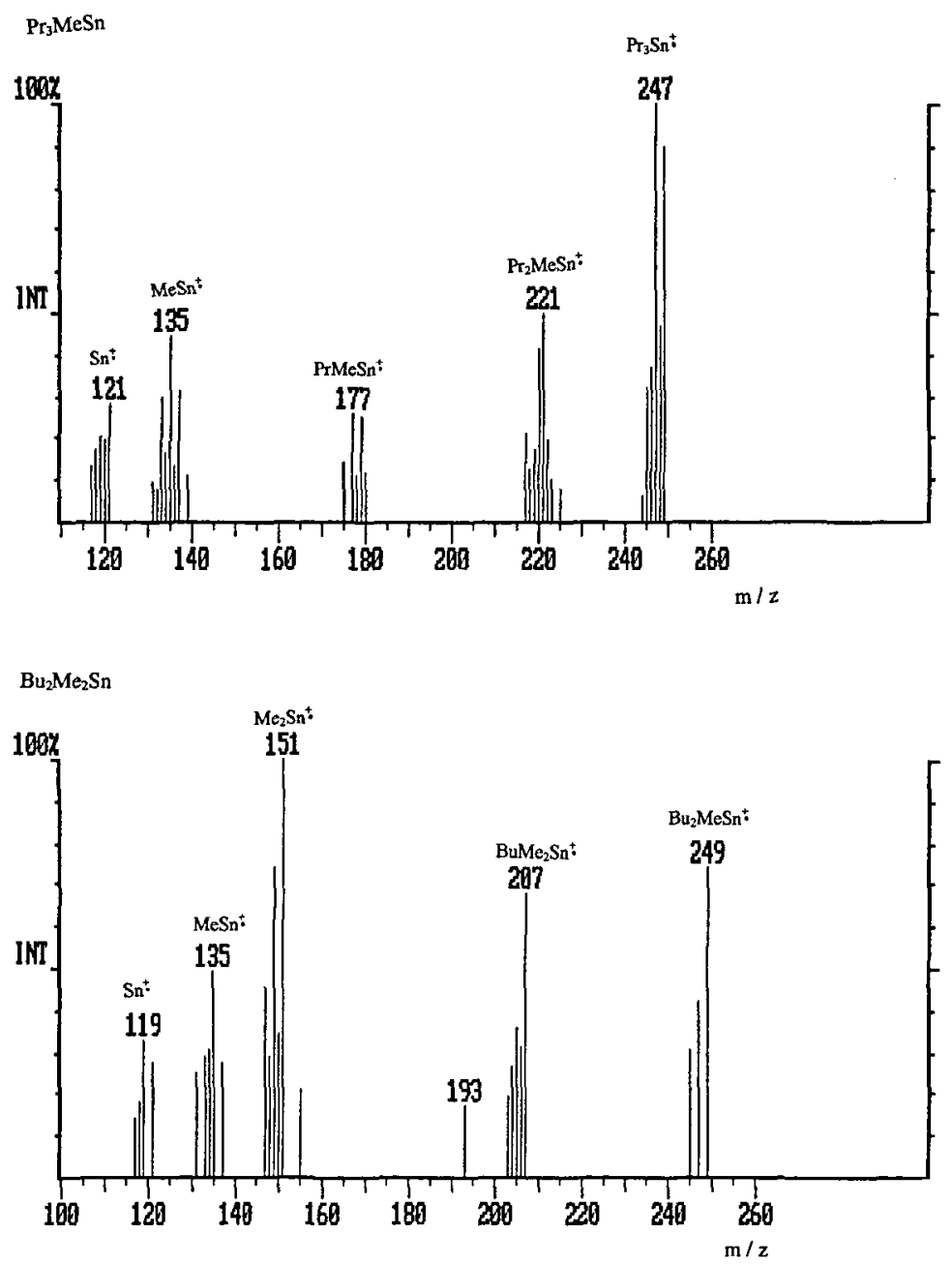

FIGURE 2(b)

FIGURE 2 Ion trap detector mass spectra of (a) $\mathrm{Bu}_{3} \mathrm{MeSn}$ and $\mathrm{BuPr}_{3} \mathrm{Sn}$ and (b) $\mathrm{Pr}_{3} \mathrm{MeSn}$ and $\mathrm{Bu}_{2} \mathrm{Me}_{2} \mathrm{Sn}$.

Using the same technique, we established the coelution of $\mathrm{Bu}_{2} \mathrm{Me}_{2} \mathrm{Sn}$ with $\mathrm{MePr}_{3} \mathrm{Sn}$, the propylation product of monomethyltin: the fragment ion cluster with $m / z$ value $146-152$, corresponding to $\left[\mathrm{Me}_{2} \mathrm{Sn}\right]^{+}$, characterizes $\mathrm{Bu}_{2} \mathrm{Me}_{2} \mathrm{Sn}$ while $m / z 216-222$ belonging to fragment ion $\left[\mathrm{MePr}_{2} \mathrm{Sn}\right]^{+}$characterizes $\mathrm{MePr}_{3} \mathrm{Sn}$ (Figure 2(b)). 


\section{RESULTS AND DISCUSSION}

\section{Butyltin Species in Bulk Seawater}

Table III shows concentrations of TBT, DBT and MBT in seawater collected from the various stations. Only seawater from offshore site 7 was consistently free of detectable amounts of TBT and this clearly reflects the effect of water exchange with the relatively unpolluted open sea. Just within the Grand Harbour port area, at St Elmo Point (site 6), concentrations of TBT occur which exceed $20 \mathrm{ng} \mathrm{Sn} \mathrm{L}^{-1}$. The most polluted waters appear to be in areas of the inner harbour next to the major local drydocks (sites 2,3). Butyltin concentrations collected from sites proximate to the yacht marinas are highest in summer and this is caused presumably by the launching of freshly painted pleasure craft at this time of year. There is no control over the use of TBTbased antifouling paints in Malta and, using trade statistics, we have estimated that about $3800 \mathrm{~L}$ are used annually on small seacraft. The shipbuilding and ship repair industry uses around 4 million $\mathrm{L} \mathrm{y}^{-1}$. No correlation appears to exist between season and TBT concentration in waters adjacent to the drydocks. Here, butyltin pollution should be mainly determined by shipyard activities related to hull cleaning operations. We estimate that high pressure hosing of hulls of large crude oil carriers as typically visit the drydocks generates about 600 tonnes of waste water which can deliver about 0.9 tonnes TBT into the marine environment. Such a source of pollution may explain why seawater levels of TBT were highest in the creeks adjacent to the drydocks. The levels of aquatic butyltin pollution in Malta harbour waters are comparable to those reported for other Mediterranean harbours and marinas [19] where [TBT] range between $<20$ to about $1000 \mathrm{ng} \mathrm{Sn} \mathrm{L}^{-1}$. As in the present study, water samples collected from sites about $1 \mathrm{~km}$ offshore Italian and Turkish harbours contained no detectable organotin compounds and this appears to confirm the view that environmental impact from organotins in Mediterranean waters is confined to inshore areas.

At sites 3 and 9, where the respective water column is 15 and $10 \mathrm{~m}$ deep, seawater samples were collected at different depths and the TBT concentration was higher towards the bottom, especially for the more polluted site 3. Such a concentration gradient could either result from a faster rate of decay of TBT in the more illuminated surface waters or it could suggest that the main supply of TBT to the water column derives from the bottom sediment, which, in drydock areas, would be enriched in grit blasting antifouling paint-containing residues. This problem needs to be investigated further since the environmental impact of contaminated sediments is not well 
TABLE III Concentrations of butyltin, methyltin and phenyltin species in bulk seawater and sediment

\begin{tabular}{|c|c|c|c|c|c|c|c|c|c|c|c|c|}
\hline \multirow[t]{2}{*}{ Sample \# } & \multirow{2}{*}{$\begin{array}{l}\text { Season when } \\
\text { collected }\end{array}$} & \multirow[t]{2}{*}{ Site \# } & \multicolumn{5}{|c|}{ Seawater $^{\mathrm{b}}\left(\mu \mathrm{g} \mathrm{Sn} \mathrm{L}^{-1}\right)$} & \multicolumn{5}{|c|}{ Sediment $\left(\mu \mathrm{g} \mathrm{Sn}^{-1}\right)$} \\
\hline & & & $\mathrm{Bu}_{3} \mathrm{Sn}^{+}$ & $\mathrm{Bu}_{2} \mathrm{Sn}^{2+}$ & $\begin{array}{c}\mathrm{BuSn}^{3+} \\
\text { (coeluting } \\
\text { with } \\
\mathrm{MeBu}_{3} \mathrm{Sn} \text { ) }\end{array}$ & $P h_{2} \mathrm{Sn}^{2+}$ & $P h S n^{3+}$ & $\mathrm{Bu}_{3} \mathrm{Sn}^{+}$ & $B u_{2} S n^{2+}$ & $\begin{array}{c}\mathrm{BuSn}^{3+} \\
\text { (coeluting } \\
\text { with } \\
\left.\mathrm{MeBu}_{3} \mathrm{Sn}\right)\end{array}$ & $\mathrm{Ph}_{2} \mathrm{Sn}^{2+}$ & $\mathrm{PhSn}^{3+}$ \\
\hline 1 & S & 1 (Marsa) & 0.028 & 0.018 & 0.013 & & & 0.21 & 0.041 & 0.090 & & \\
\hline 2 & A & 1 & 0.013 & 0.030 & 0.007 & & & nd & nd & 0.053 & & \\
\hline 3 & W & 1 & 0.019 & 0.009 & 0.013 & & & & & & & \\
\hline 4 & $\mathrm{~S}$ & 2 (Ras Hanzir) & 0.038 & 0.042 & 0.026 & & & & & & & \\
\hline 5 & A & 2 & 0.31 & 0.13 & 0.12 & 0.24 & 0.89 & & & & & \\
\hline 6 & W & 2 & 0.031 & 0.015 & nd & & & 0.11 & 0.059 & 0.11 & & \\
\hline 7 & s & 3 (French Creek) & 0.034 & 0.031 & 0.049 & & & & & & & \\
\hline 8 & $\mathrm{~A}$ & 3 & 0.005 & 0.011 & nd & & & nd & nd & nd & & \\
\hline 9 & W & 3 & 0.050 & 0.023 & nd & & & 0.28 & 0.12 & 0.12 & & \\
\hline 10 & W & $3^{\mathrm{c}}$ & 0.096 & 0.037 & 0.005 & & & & & & & \\
\hline 11 & W & $3^{d}$ & 0.29 & 0.089 & 0.085 & & & & & & & \\
\hline 12 & $\mathrm{~S}$ & 4 (Drydock Creek) & nd & nd & nd & & & & & & & \\
\hline 13 & $\mathrm{~A}$ & 4 & 0.012 & 0.020 & 0.008 & & & & & & & \\
\hline 14 & W & 4 & 0.055 & 0.039 & nd & & 0.050 & & & & & \\
\hline 15 & $\mathrm{~s}$ & 5 (Rinella Creek) & 0.017 & 0.037 & 0.026 & & & 0.056 & 0.053 & 0.20 & & 0.070 \\
\hline 16 & A & 5 & 0.012 & 0.018 & 0.005 & 0.043 & 0.063 & 0.026 & 0.041 & $0.063^{*}$ & & \\
\hline 17 & $\mathrm{~W}$ & 5 & 0.027 & 0.014 & nd & & & & & & & \\
\hline 18 & $\mathrm{~S}$ & 6 (St Elmo Point) & 0.074 & 0.031 & 0.010 & & & 0.030 & 0.32 & 0.35 & & \\
\hline 19 & A & 6 & nd & 0.007 & nd & & & & & & & \\
\hline 20 & W & 6 & 0.025 & 0.023 & nd & & & & & & & \\
\hline 21 & $\mathrm{~S}$ & 7 (Offshore site) & nd & 0.011 & nd & & & & & & & \\
\hline 22 & $\mathrm{~A}$ & 7 & nd & nd & nd & & & & & & & \\
\hline 23 & $\mathrm{~W}$ & 7 & nd & nd & nd & & & & & & & \\
\hline 24 & $S$ & $\begin{array}{c}8 \text { (Marsamxett } \\
\text { Harbour) }\end{array}$ & 0.049 & 0.024 & nd & & & 0.022 & 0.040 & 0.080 & & \\
\hline
\end{tabular}




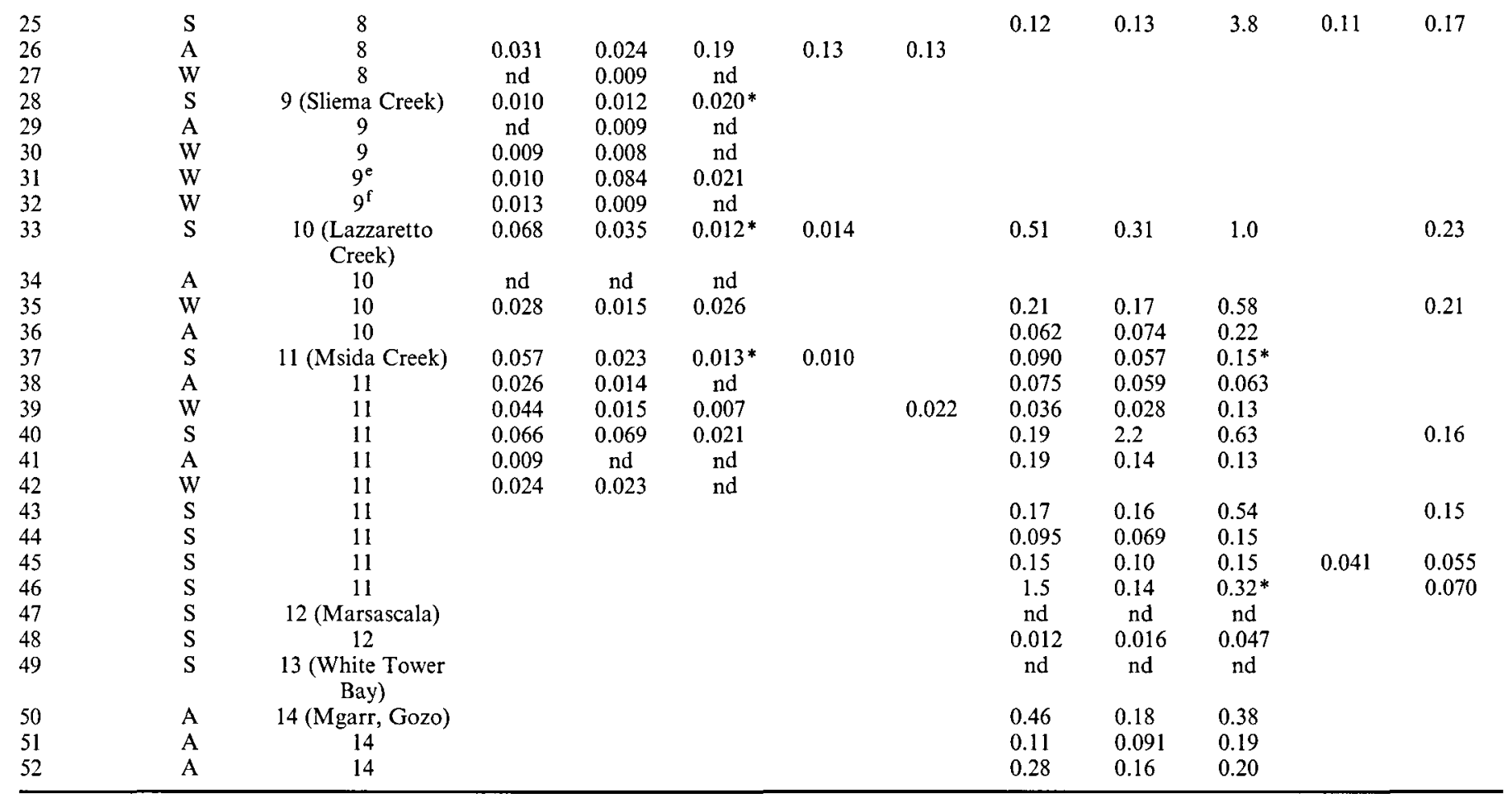

${ }^{\mathrm{a}} \mathrm{S}=$ summer (June/July 1993); A = autumn (Sept/Oct 1993); W = winter (Jan/Feb 1994); ${ }^{b}$ Unless otherwise indicated, seawater was sampled at $\mathrm{I} \mathrm{m}$ depth; ${ }^{\mathrm{c}}$ Sampling depth $5 \mathrm{~m}$; ${ }^{\mathrm{d}} 14 \mathrm{~m} ;{ }^{\mathrm{e}} 4 \mathrm{~m} ;{ }^{\mathrm{C}} 9 \mathrm{~m}$; nd = not detected; * No evidence of coelution. 
understood and concerns have been expressed over the remobilization of organotins by dredging operations [20].

In $44 \%$ of seawater samples, the trend in concentration of butyltins, namely, $\left[\mathrm{Bu}_{3} \mathrm{Sn}^{+}\right]>\left[\mathrm{Bu}_{2} \mathrm{Sn}^{2+}\right]>\left[\mathrm{BuSn}^{3+}\right]$ accords with the major mode of degradation of TBT in the aquatic environment for a sustained input of the primary pollutant.

\section{Phenyltins in Bulk Seawater}

Phenyltin species, namely $\mathrm{PhSn}^{3+}$ and $\mathrm{Ph}_{2} \mathrm{Sn}^{2+}$, were found in seawater samples collected from 6 of the 11 sites (Table III): all six sites are inside the Valletta harbours and were generally contaminated with butyltins. Aryltin concentrations in Malta waters are comparable to those found in seawater from marinas and drydocks on the Spanish Mediterranean coast [1]. In a more recent study, seawater from these same areas has yielded $\mathrm{PhSn}^{3+}(20-$ $40 \mathrm{ng} \mathrm{Sn} \mathrm{L}^{-1}$ ) as the main aryltin form [22]. Much lower concentrations of triphenyl and diphenyltin (but no monophenyltin) were reported in water from the Italian La Spezia Gulf [3]. The presence of $\mathrm{Ph}_{2} \mathrm{Sn}^{2+}$ and $\mathrm{PhSn}^{3+}$ in seawater is presumably a result of degradation of $\mathrm{Ph}_{3} \mathrm{Sn}^{+}$, a species with a half life of the order of several days [21]. We found the greatest concentrations of these aryltins in seawater sample [5] which also contained the highest level of TBT. From trade statistics, we established that triphenyltin containing agricultural pesticides have not been imported or used in Malta and it is likely that phenyltins in the local marine environment also originate from antifouling marine paints.

\section{Butyltin Species in Sediments}

Information on organotin compounds in sediments for Mediterranean sites is rather limited. We have found that, as observed elsewhere $[23,24]$, concentrations of sedimentary TBT (Table III) correlate with the density of marine craft in the area of the sediments, highest values being found in marinas. It is notable that, in marina sites 10 and 11 , sediments are substantially more contaminated with TBT than those in areas which are dedicated to ship repair (sites 3,5) and transportation (sites 8, 14). This trend is less clear for tin pollution in the water column. The highest TBT concentration (at site 11) was $1.4 \mu \mathrm{g} \mathrm{Sn} \mathrm{g}^{-1}$ and this is almost five times the value reported for sediments from the French Mediterranean coast [23] and is similar to values in Alexandria harbour sediment [19]. Butyltin concentrations in Malta are also generally higher than those reported for the Sado Estuary, Portugal [23,24]. 
TBT is known to cause imposex in marine gastropods. In a recent study [25] it was shown that all specimens of female species of Hexaplex trunculus collected from several Malta sites were imposexed to some degree. The biological availability of sedimentary butyltins is not well understood. The results with $H$. trunculus showed that most of the butyltin body burden was associated with the digestive gland and gonads and this may suggest that the snails acquire the pollutants through feeding. The abundance of TBT in Malta harbour sediments may explain the observed ubiquity of imposex in these gastropods.

\section{Phenyltin Species in Sediments}

The most prevalent phenyltin form found in sediments was $\mathrm{PhSn}^{3+}$ occurring in 8 samples collected from the harbour areas; only two samples contained $\mathrm{Ph}_{2} \mathrm{Sn}^{2+}$ and no sample contained triphenyltin (Table III). Cai et al. [2] mention the presence of monophenyltin in a sediment from a Spanish marina at similar concentration to that reported here but this compound was found accompanied by triphenyl and diphenyltin. We found no correlation between the abundance of total aryltin and total butyltin in sediments.

\section{Butyltin Species in the Surface Microlayer}

Samples of surface microlayer were collected from the offshore station and from the Valletta harbours area only. There was no apparent correlation between location and organotin levels: this may reflect the relative mobility of the medium compared with bulk seawater. Ten samples $(14 \%)$ were free of all types of organotins and this absence may possibly result from discontinuities in the layer or from an unevenness in its chemical composition. When butyltins were revealed (Table IV), their concentrations tended to be higher than corresponding aquatic ones, sometimes by factors $>10$. Thus, for sample 21 (site 11), [DBT] in the microlayer is 31 times the highest summer concentration of the species in the water column at Msida Creek; microlayer [TBT] in sample 24 from the same site is 5 times the highest winter aquatic concentration measured in the same area. One expects to find enhancement of lipophilic organotins in the hydrophobic microlayer and this effect has indeed been observed in samples collected from the Atlantic ocean and Canadian lakes [26-28]. Also, in the microlayer, the physical conditions and microbiological activity are known to be conducive towards the effective degradation of TBT into its metabolites [20]. Only 4 microlayer samples 
TABLE IV Concentrations $\left(\mu \mathrm{Sn} \mathrm{L}^{-1}\right)$ of butyltin and methyltin species in surface microlayer

\begin{tabular}{|c|c|c|c|c|c|}
\hline Sample \# & $\begin{array}{l}\text { Season when } \\
\text { collected }^{\mathrm{a}}\end{array}$ & Site \# & $B u_{3} \mathrm{Sn}^{+}$ & $B u_{2} S n^{2+}$ & $\begin{array}{c}\mathrm{BuSn}^{3+}(\text { coeluting } \\
\left.\text { with } \mathrm{MeBu}_{3} \mathrm{Sn}\right)\end{array}$ \\
\hline 1 & A & 1 (Marsa) & & 0.16 & \\
\hline 2 & W & 1 & & 0.16 & \\
\hline 3 & A & 2 (Ras Hanzir) & & 0.52 & \\
\hline 4 & W & 2 & & 0.12 & \\
\hline 5 & A & 3 (French Creek) & & 0.25 & \\
\hline 6 & A & 4 (Drydock Creek) & & 0.61 & \\
\hline 7 & $\mathrm{~S}$ & 5 (Rinella Creek) & 0.14 & 0.23 & \\
\hline 8 & W & 5 & & 0.16 & \\
\hline 9 & $\mathrm{~S}$ & 6 (St Elmo Point) & & & 2.0 \\
\hline 10 & A & 6 & & 0.43 & \\
\hline 11 & $\mathrm{~S}$ & 7 (Offshore site) & & 0.34 & \\
\hline 12 & A & 8 (Marsamxett Harbour) & & 0.007 & \\
\hline 13 & W & 8 & & 0.92 & \\
\hline 14 & S & 9 (Sliema Creek) & & 0.16 & 1.5 \\
\hline 15 & $\mathrm{~S}$ & 9 & & 0.49 & \\
\hline 16 & A & 9 & & 0.99 & \\
\hline 17 & W & 9 & & 0.13 & \\
\hline 18 & A & 10 (Lazzaretto Creek) & & 0.37 & \\
\hline 19 & $\mathrm{~S}$ & 11 (Msida Creek) & & 3.1 & 31 \\
\hline 20 & $\mathrm{~S}$ & 11 & & 0.56 & \\
\hline 21 & $\mathrm{~S}$ & 11 & & 2.2 & \\
\hline 22 & W & 11 & 0.13 & & 0.14 \\
\hline 23 & W & 11 & & 0.18 & \\
\hline 24 & W & 11 & 0.21 & & \\
\hline 25 & W & 11 & 0.095 & & \\
\hline
\end{tabular}

${ }^{\text {a }}$ S = summer (June/July 1993); A = autumn (Sept/Oct 1993); W = winter (Jan/Feb 1994).

found to contain organotins ( $7 \%$ ) hosted TBT and by far the most prevalent butyltin was DBT. No phenyltins were found in any sample of microlayer.

\section{Tetrasubstituted Organotins}

The occurrence of chromatographic peaks with retention times and ITD mass spectra corresponding to methylbutyltins $\mathrm{Me}_{n} \mathrm{Bu}_{(4-n)} \mathrm{Sn}(n=1-3)$ represent the first report of such compounds in the marine environment. Such tetraorganotin forms have previously only been reported rarely and at low concentrations in fresh water environments [14,27]. We have encountered these compounds primarily in sediments but also in microlayer and bulk seawater samples (Table V).

We considered the possibility that these compounds could represent analytical artifacts arising from the use of microlitre quantities of methanol as a solvent for tripentyltin chloride. We carried out several control experiments with aqueous solutions of standard butyltin chlorides to test this hypothesis but no peaks corresponding to such species were observed. Also, the fact that 
TABLE $V$ Concentrations of tetraalkyltins in bulk seawater and surface microlayer $\left(\mu \mathrm{gSnL} \mathrm{L}^{-1}\right)$ and in sediment $\left(\mu \mathrm{gSng}^{-1}\right)$

\begin{tabular}{|c|c|c|c|c|}
\hline Sample & $\begin{array}{l}\text { Season when } \\
\text { collected }^{\mathrm{a}}\end{array}$ & Site & $M e_{3} B u S n$ & $\begin{array}{c}\mathrm{Me}_{2} \mathrm{Bu}_{2} \mathrm{Sn} \text { (coeluting } \\
\text { with } \mathrm{MeSn}{ }^{3+} \text { ) }\end{array}$ \\
\hline \multicolumn{5}{|l|}{ Seawater } \\
\hline \multicolumn{5}{|l|}{ Sediment } \\
\hline 9 & W & 3 (French Creek) & 0.21 & \\
\hline 24 & $\mathrm{~S}$ & 8 (Marsamxett Harbour) & 0.26 & 0.12 \\
\hline 25 & $\mathrm{~S}$ & 8 & 1.1 & \\
\hline 33 & $\mathrm{~S}$ & 10 (Lazzaretto Creek) & 5.6 & $0.22 *$ \\
\hline 36 & A & 10 & 1.2 & 0.30 \\
\hline 37 & $\mathrm{~S}$ & 11 (Msida Creek) & 1.9 & \\
\hline 38 & A & 11 & 1.6 & \\
\hline 39 & W & 11 & & 0.10 \\
\hline 41 & A & 11 & 2.1 & \\
\hline 43 & S & 11 & & 0.29 \\
\hline 44 & $\mathrm{~S}$ & 11 & 0.077 & \\
\hline 46 & $\mathrm{~S}$ & 11 & 0.50 & \\
\hline 47 & $\mathrm{~S}$ & 12 (Marsascala) & 0.44 & \\
\hline 48 & $\mathbf{S}$ & 12 & & 0.076 \\
\hline 50 & A & 14 (Mgarr, Gozo) & 1.6 & \\
\hline 51 & A & 14 & 3.4 & \\
\hline 52 & A & 14 & 9.0 & \\
\hline \multicolumn{5}{|c|}{ Microlayer } \\
\hline 4 & W & 2 (Ras Hanzir) & & 0.40 \\
\hline 61 & W & 3 (French Creek) & & 1.2 \\
\hline 47 & A & 5 (Rinella Creek) & & 1.5 \\
\hline 10 & A & 6 & 140 & \\
\hline 28 & S & $\begin{array}{l}7 \text { (Site offshore Grand } \\
\text { Harbour) }\end{array}$ & 14 & \\
\hline 13 & W & 8 (Marsamxett Harbour) & & 1.4 \\
\hline 15 & $\mathrm{~S}$ & 9 & & 3.4 \\
\hline 16 & A & 9 & & 17 \\
\hline 19 & S & 11 (Msida Creek) & & 20 \\
\hline
\end{tabular}

${ }^{a} S=$ summer (June/July 1993); A = autumn (Sept/Oct 1993); $W=$ winter (Jan/Feb 1994); ${ }^{*}$ No evidence of coelution.

several field samples of sediments and seawater were found to contain butyltins but had no peaks corresponding to butylmethyltins argues strongly against their formation as artifacts of the analytical procedure.

Trimethylbutyltin appears as peak 1 in Figure 3(a) pertaining to a sedimentary extract from site 10; the compound has an ITD mass spectrum as shown in Figure 3(b). The compound was found in almost half of the 29 sediments analysed in concentrations ranging from $0.08-9.0 \mu \mathrm{g} \mathrm{Sn} \mathrm{g}^{-1}$ but it was not detected in any of the bulk seawater samples. At Mgarr harbour (site 14), its concentration represents $94 \%$ of total organotins in the sediment. $\mathrm{Me}_{3} \mathrm{BuSn}$ was also found in two surface microlayer samples, one from the 


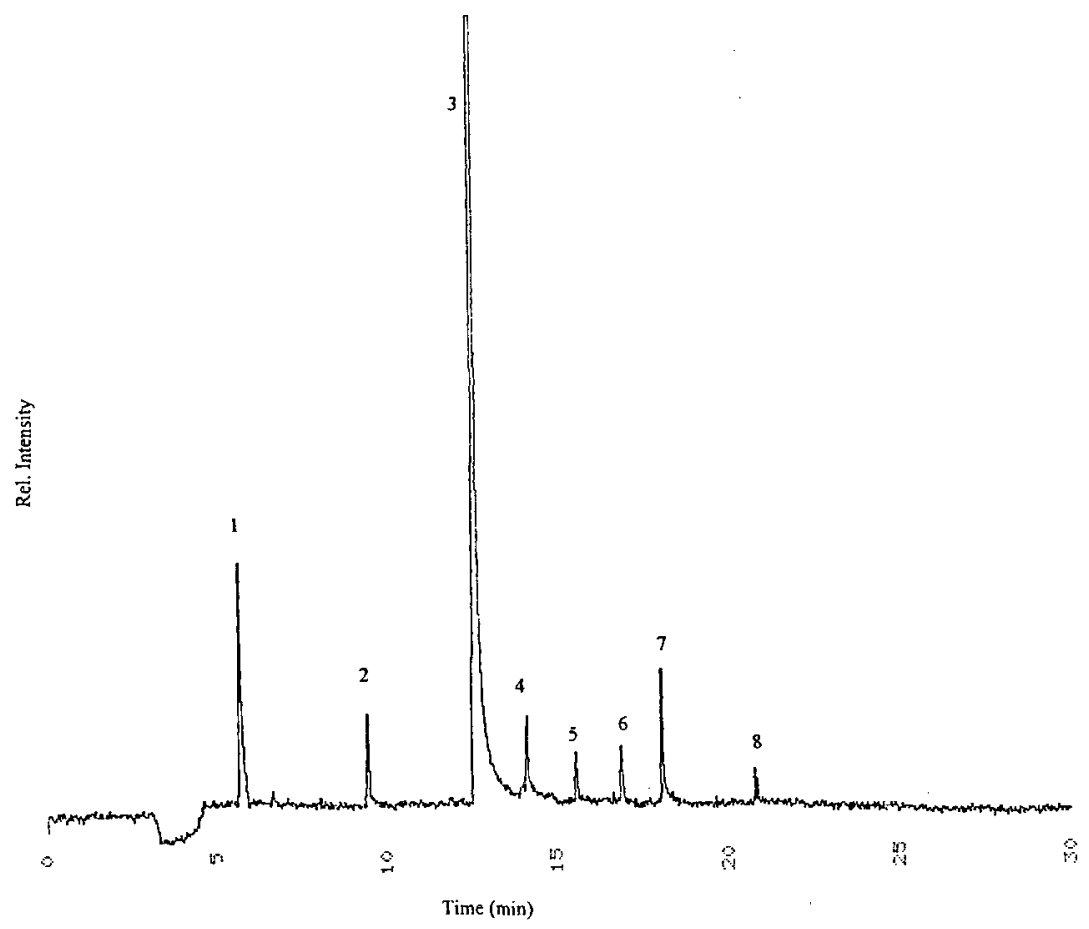

FIGURE 3(a) Chromatogram showing the presence of $\mathrm{Me}_{3} \mathrm{BuSn}$ (peak 1) found in extract from sediment sample 36; other peak identities as follows: $2=\mathrm{Me}_{2} \mathrm{Bu}_{2} \mathrm{Sn} / \mathrm{MeSn}^{3+}, 3=\mathrm{Sn}^{4+}$, $4=\mathrm{MBT}, 5=\mathrm{DBT}, 6=\mathrm{TBT}, 7=\mathrm{Bu}_{4} \mathrm{Sn}$ (int. stand.), $8=\mathrm{Pe}_{3} \mathrm{Sn}^{+}$(rec. stand.).

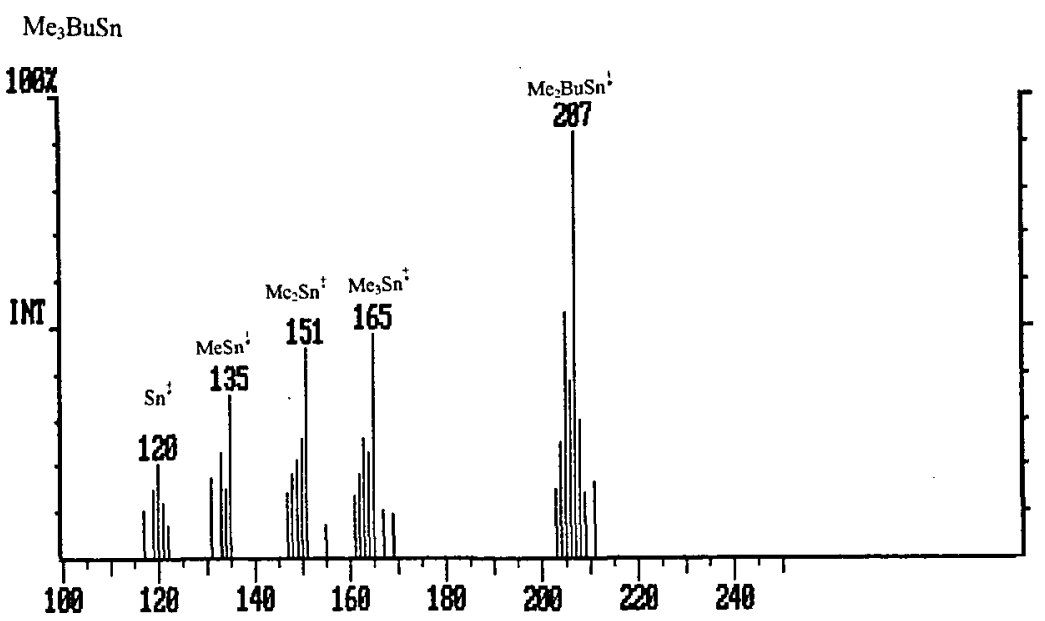

FIGURE 3(b) Ion trap detector mass spectrum of $\mathrm{Me}_{3} \mathrm{BuSn}$. 
offshore station $\left(14 \mu \mathrm{g} \mathrm{Sn} \mathrm{L}^{-1}\right)$ and the other from site 6 in Grand Harbour $\left(140 \mu \mathrm{g} \mathrm{Sn} \mathrm{L}^{-1}\right)$. For the latter sample, the concentration of trimethylbutyltin is 2000 times the highest seawater TBT value $\left(0.07 \mu \mathrm{g} \mathrm{Sn} \mathrm{L}^{-1}\right)$ measured in the same area. The fact that even in the offshore site, the surface microlayer (sample 28) was found to contain $14 \mu \mathrm{g} \mathrm{Sn} \mathrm{L}^{-1}$ of trimethylbutyltin is significant and suggests that TBT-related contamination could persist in a modified form and at very high concentration in the environment. The presence of toxic organotin compounds at such levels in the microlayer is probably detrimental to the neuston [28] and our results should raise concerns with regards to Mediterranean fisheries and aquaculture.

Using gas chromatography-ITD mass spectrometry, we established the presence, in all three environmental compartments, of two other methylbutyltins, namely, methyltributyltin and dimethyldibutyltin. ITD mass spectrometry revealed that, in all but 9 samples ( 6 sediment and 3 seawater), the total ion chromatographic peak corresponding to propylated MBT $\left(\mathrm{BuPr}_{3} \mathrm{Sn}\right)$ was accompanied by fragment ions originating exclusively from methyltributyltin. The presence of such species would have gone undetected if the gas chromatographic analysis had been restricted to flame photometric detection. The peak corresponding to dimethyldibutyltin has a shorter retention time than any of the propylated products of degradation of TBT, but it does coelute with isomeric methyltripropyltin. Indeed, in all but one sample (sediment 33), the ITD total ion peak corresponding to this organotin species was found to possess a contribution from both isomers.

Unfortunately, ITD mass spectrometry does not allow for a quantitative estimation of the isomeric composition of coeluting mixtures. As observed for trimethylbutyltin, sedimentary concentrations of dimethyldibutyltin are comparable or higher than corresponding values of TBT and are generally associated with areas which are contaminated with TBT.

There has never been any chemical industry related to organotins in Malta and these compounds in the local marine environment presumably originate from inputs related to products containing TBT, i.e. antifouling marine paints. The fact that (except for the surface microlayer) methylbutyltins are generally found in TBT-polluted environments strongly implies a connection between these species and TBT and suggests that methyltributyltin is obtained by direct methylation of TBT. Similarly, $\mathrm{Me}_{2} \mathrm{Bu}_{2} \mathrm{Sn}$ could form from DBT and $\mathrm{Me}_{3} \mathrm{BuSn}$ from MBT. From our results it appears that such environmental methylation processes are apparently of particular importance in sediments: presumably, the more biologically active sedimentary environment accounts for the greater degree of success in such transformations and may suggest that the mechanism is biotic. 
Being neutral molecules, methylbutyltins are more volatile than formally ionic TBT and its debutylated analogues. This leads one to speculate on the possibility that dredging operations of polluted sediments could cause these compounds to mobilize into the water column and eventually into the atmosphere. Indeed their presence at high concentration in the surface microlayer implies that degassing of these substances into marine air is a likely possibility.

Our results suggest that direct methylation of TBT and that of its debutylated metabolites may play a role in the geochemical cycling of tin which could be significant at least in certain environments.

\section{CONCLUSIONS}

The presence of organotin species in seawater, surface microlayer and sediments in the coastal zone of Malta is reported in detail for the first time. The concentrations of TBT in seawater inside Valletta harbours frequently exceed $20 \mathrm{ng} \mathrm{Sn} \mathrm{L}^{-1}$ but are undetectable in open sea $1.6 \mathrm{~km}$ offshore indicating the strongly local nature of the problem. In waters of yacht marinas, TBT levels peak during the summer but butyltin pollution of waters next to the drydocks is constantly high and may be influenced by shipyard operations involving hull cleaning. In sediments, TBT concentrations correlate with the density of marine craft in the area and are higher for yacht marinas. Aryltins found in bulk seawater and sediments were $\mathrm{Ph}_{2} \mathrm{Sn}^{2+}$ and $\mathrm{PhSn}^{3+}$ and locally presumably originate from antifouling marine paint.

Mixed methylbutyltins, namely, $\mathrm{MeBu}_{3} \mathrm{Sn}, \mathrm{Me}_{2} \mathrm{Bu}_{2} \mathrm{Sn}$ and $\mathrm{Me}_{3} \mathrm{BuSn}$ were found in surface layer and especially in sediments, although $\mathrm{MeBu}_{3} \mathrm{Sn}$ was also detected in bulk seawater. In general, for bulk seawater and sediments, these compounds are associated with environments that are contaminated with significant levels of TBT. However, this is not the situation for the surface microlayer where even the offshore site contains microgram $\mathrm{L}^{-1}$ levels of these organotins. The occurrence of mixed methylbutyltins suggests that direct environmental methylation of TBT, DBT and MBT may constitute a significant pathway in the geochemistry of organotin compounds, at least, in certain marine environments.

\section{Acknowledgement}

This work was partly supported by the Commission of European Communities through its MedSPA programme under contract number MedSPA91-1/UK/002/INT/06. 


\section{References}

[1] I. Tolosa, L. Merlini, N. De Bertrand, J. M. Bayona and J. Albaiges, Occurrence and fate of tributyl- and triphenyltin compounds in western Mediterranean coastal enclosures, Environ. Toxicol. Chem. 11, 145-155 (1992).

[2] Y. Cai, R. Alzaga and J. M. Bayona, In situ derivatization and supercritical fluid extraction for the simultaneous determination of butyltin and phenyltin compounds in sediment, Anal. Chem. 66, 1161-1167 (1994).

[3] A. M. Caricchia, S. Chiavarini, C. Cremisini, M. Fantini and R. Morabito, Monitoring of organotins in the La Spezia Gulf - II. Results of the 1990 sampling campaigns and concluding remarks, Sci. Total Environ. 101, 217-227 (1991).

[4] M. D. Muller, Comprehensive trace level determination of organotin compounds in environmental samples using high-resolution gas chromatography with flame photometric detection, Anal. Chem. 59, 617-623 (1987).

[5] S. J. Blunden, L. A. Hobbs and P. J. Smith, The environmental chemistry of organotin compounds. In Environmental Chemistry (Edited by H. J. M. Bowen), pp. 51-77. Royal Society of Chemistry, London (1984).

[6] A. M. Falke and J. H. Weber, Variations in concentrations of methyltin compounds and inorganic tin in Spartina alterniflora and porewater in the Great Bay Estuary (NH) during the 1991 growing season, Environ. Sci. Technol. 14, 851-859 (1993).

[7] W. P. Blair, J. A. Jackson, G. J. Olson, F. E. Brinckman and W. P. Iverson, Biotransformation of Tin, Proceedings of the Int. Conf. Heavy Met. Environ. pp. 235-242. (1981).

[8] L. E. Hallas, J. C. Means and J. J. Cooney, Methylation of tin by estuarine microorganisms, Science 215, 1505-1507 (1982).

[9] J. R. Ashby and P. J. Craig, Environmental methylation of tin: an assessment, Sci. Total Environ. 73, 127-133 (1989a).

[10] D. S. Lee and J. H. Weber, Methylation of $\mathrm{Sn}(\mathrm{II})$ by methyl iodide in porewater, Appl. Organomet. Chem. 11, 435-440 (1988).

[11] S. Rapsomanikis and J. H. Weber, Environmental implications of methylation of tin(II) and methyltin(IV) ions in the presence of manganese dioxide, Environ. Sci. Technol. 19, 352-356 (1985).

[12] O. F. X. Donard and J. H. Weber, Volatilization of tin as stannane in model anoxic environment, Nature 332, 6162, 339-341 (1988).

[13] J. A. Jackson, W. R. Blair, F. E. Brinckman and W. P. Iverson, Gas-chromatographic speciation of methylstannanes in the Chesapeake Bay using purge and trap sampling with a tin-selective detector, Environ. Sci. Technol. 16, 110-119 (1982).

[14] R. J. Maguire, Butyltin compounds and inorganic tin in sediment in Ontario, Environ. Sci. Technol. 18, 291-294 (1984).

[15] R. J. Maguire and H. Huneault, Determination of butyltin species in water by gas chromatography with flame photometric detection, J. Chromatogr. 209, 458-462 (1981).

[16] G. W. Harvey and L. A. Burzell, A simple microlayer method for small samples, Limnol. Oceanogr. 17, 156-157 (1972).

[17] M. J. Waldock, J. E. Thain and M. E. Waite, The distribution and potential toxic effects of tributyltin in UK estuaries during 1986, Appl. Organomet. Chem. 1, 287-301 (1987).

[18] J. R Ashby and P. J. Craig, New method for the production of volatile organometallic species for analysis from the environment, some butyltin levels in UK sediments, Sci. Total Environ. 78, 219-232 (1989b).

[19] G. P. Gabrielides, C. Alzieu, J. W. Readman, E. Bacci, O. Aboul Dahab and I. Salihoglu, Medpol survey of organotins in the Mediterranean, Mar. Pollut. Bull. 233-237 (1990).

[20] M. D. Muller, L. Renberg and G. Rippen, Tributyltin in the environment - sources, fate and determination. An assessment of present status and research needs, Chemosphere 18, 2015-2042 (1989).

[21] R. Bock, In Residue Reviews (Edited by F. A. Gunther), Vol. 79, pp. 216-222. Springer, Berlin Heidelberg, New York (1981).

[22] Y. Cai and J. M. Bayona, Simultaneous speciation of butyl-, phenyl-, and cyclohexyltin compounds in aqueous matrices using ethylation followed by solid-phase trace enrichment, SFE and gas chromatographic determination, J. Chromatogr. Sci. 33, 89-97 (1995). 
[23] P. Quevauviller and O. F. X. Donard, Variability of butyltin determination in water and sediment samples from European coastal environments, Appl. Organomet. Chem. 4, 353-367 (1990).

[24] P. Quevauviller, R. Lavigne, R. Pinel and M. Astruc, Organotins in sediments and mussels from the Sado estuarine system (Portugal), Environ. Pollut. 57, 149-166 (1989).

[25] V. Axiak, A. J Vella, D. Micallef, P. Chircop and B. Mintoff, Imposex in Hexaplex trunculus (Gastropoda: Muricidae): first results from biomonitoring of tributyltin contamination in the Mediterranean, Mar. Biol. 121, 685-691 (1995).

[26] J. J. Cleary and A. R. D. Stebbing, Organotin and total tin in coastal waters of southwest England, Mar. Pollut. Bull. 16, 350-355 (1985).

[27] R. J. Maguire, R. J. Tkacz, Y. K. Chau, G. A. Bengert and P. T. S. Wong, Occurrence of organotin compounds in water and sediment in Canada, Chemosphere 15, 253-274 (1986).

[28] J. T. Hardy and J. Cleary, Surface microlayer contamination and toxicity in the German Bight, Mar. Ecol. Prog. Ser. 91, 203-210 (1992). 